\title{
O Egito entre o Islã e o liberalismo: a trajetória constitucional de um Estado híbrido
}

\author{
Márcia de Paiva Fernandes \\ Mestra pela Universidade Estadual de Campinas, Campinas, Brasil \\ mp.fernandes@hotmail.com
}

Frederico Normanha Ribeiro de Almeida Professor Doutor da Universidade Estadual de Campinas, Campinas, Brasil fnralmeida@gmail.com

Resumo $\mathrm{O}$ objetivo deste artigo é analisar a expansão da dimensão religiosa na política do Egito com a adoção da Constituição de 1971 e como ela foi alterada nas Constituições de 2012 e de 2014. Para tanto, são apresentadas a proposta política da tradição islâmica, bem como a da liberal, e as maneiras pelas quais ambas passaram a conviver no Egito, conferindo ao país um aspecto híbrido. Em seguida, uma síntese da trajetória constitucional egípcia de 1923 a 1964 é exposta, e, logo após, é feita a análise das Constituições acima mencionadas. Por fim, as considerações finais mostram os impactos da manipulação da dimensão religiosa nos documentos constitucionais egípcios e como ela é instrumentalizada para o alcance de objetivos políticos.

Palavras-chave: Constituição, Egito, Estado híbrido, Islã, liberalismo.

\section{Introdução}

A história política do Egito tem chamado a atenção de pesquisadores tanto por sua antiguidade quanto por sua complexidade. Ademais, o impacto que os eventos políticos egípcios causam nos demais países do Oriente Médio é um outro motivo que desperta o interesse pela sua compreensão. Porém, um entendimento mais adequado da política do Egito contemporâneo deve também considerar as dinâmicas por detrás da sua própria formação como um Estado-nação moderno. 
Pela leitura de suas Constituições, é possível observar que a coexistência entre princípios oriundos das tradições islâmica e liberal é uma dessas dinâmicas. Essa coexistência ao longo do tempo passou por modificações que resultaram no gradativo aumento do espaço concedido à tradição islâmica, e os ajustes na acomodação entre elementos liberais e islâmicos podem ser observados em todas as Constituições egípcias, embora nem sempre para implementar uma agenda liberal ou islâmica específica. $\mathrm{O}$ que ocorre, na realidade, é uma manipulação da presença de tais elementos nos documentos constitucionais do Egito que, a rigor, tem concedido um grande destaque para a tradição islâmica, principalmente a partir da Constituição de 1971.

Desse modo, o objetivo desse artigo é analisar o motivo por detrás dessa expansão nessa Constituição e como ela foi alterada nas Cartas de 2012 e de 2014. Para tanto, será preciso compreender as propostas políticas das tradições islâmica e liberal e como elas passaram a coexistir no Egito para, em seguida, apresentar um breve panorama da trajetória constitucional do país da década de 1920 até a de 1960. Posteriormente, serão analisadas as Constituições adotadas nos períodos supracitados para, finalmente, apresentar nas considerações finais uma análise que englobe essas questões.

\section{A política vista sob a ótica islâmica e liberal}

O desenvolvimento do que se considera hoje como a doutrina política oriunda da tradição islâmica esteve vinculado, obviamente, à história do Islã. Entretanto, a exposição do histórico de desenvolvimento de suas características definidoras principais será breve nesse artigo devido à sua grande complexidade. De todo modo, o que deve ser destacado é que há, no âmbito dessa tradição, um vínculo constante e robusto entre o campo político e o religioso que é resultante da interação entre Deus e o Profeta Muhammad, e dele com a comunidade dos fiéis.

A revelação divina ao Profeta, e a sua transmissão aos seus seguidores, conferia a ele uma legitimidade que superava a dimensão puramente religiosa e também englobava um aspecto político. Esse vínculo entre dimensões política e religiosa era reforçado pela existência, dentre as normas e os princípios do Islã, de prescrições relacionadas não somente à conduta individual, mas também à forma pela qual a comunidade dos muçulmanos deveria ser administrada em seus assuntos políticos, econômicos e sociais. Como essas orientações eram dadas pelo próprio Deus, elas eram ideais e suficientes e, portanto, deveriam ser implementadas pelo líder político, fosse ele o Profeta ou aqueles que o sucederam após a sua morte (Al-Ashmawy, 1994; Nazir-Ali, 2010).

O que se considera hoje como o conjunto desse tipo de prescrições do Islã foi desenvolvido de forma gradual a partir dos esforços de codificação e interpretação da revelação divina. De todo modo, a lei islâmica, comumente designada por Shari'a, era a fonte do direito que regia os seguidores do Profeta,já que nela reside - ou dela pode ser deduzida - as prescrições divinas para o campo político, o que leva à constatação de que a 
soberania e a autoridade legislativa nessa proposta política estavam vinculadas ao próprio Deus. Conforme o Islã foi se espalhando para além do território no qual a revelação ocorreu, essa proposta política também foi sendo incorporada em distintas sociedades, como no caso do Egito, e foi se tornando o modelo responsável pela sua organização e administração (Fernandes, 2017; Badie; Hermet, 1993).

Ao se deparar com comunidades religiosas distintas nesse processo de expansão, a tradição islâmica encontrou uma forma de estabelecer a convivência entre elas e os muçulmanos baseada em um entendimento próprio da noção de igualdade. Para o Islã, o Cristianismo e o Judaísmo são religiões sagradas, e, portanto, os seus seguidores, caso não queiram se converter, devem possuir o direito à liberdade religiosa e de usarem suas próprias regras religiosas para resolverem questões espirituais e de ordem pessoal. Outras comunidades religiosas não são incluídas nessa proposta de acomodação. Há, portanto, a noção de que os indivíduos são diferentes por seguirem distintas religiões e de que os direitos são concedidos a eles em função da comunidade religiosa à qual pertencem (Scott, 2010; Nazir-Ali, 2010).

Foi com esse quadro político que o modelo liberal se deparou ao chegar ao Egito, não encontrando, portanto, um vazio político para preencher. Seus princípios, entretanto, chocavam-se diretamente com a tradição política islâmica, porque, se nesta o vínculo entre religião e política constituía a sua própria essência, no caso liberal o desejo de romper essa ligação foi a principal demanda do movimento em seu início e é o que o define até hoje. O desenvolvimento do modelo liberal também foi gradual, complexo e envolveu vários atores. Seria inviável apresentá-lo em detalhes aqui, e, por isso, a exposição de suas características definidoras principais será breve.

Em oposição ao vínculo estabelecido entre os monarcas absolutistas e a Igreja Católica - e que justificava seus governos abusivos e repressores pelo fato de serem apresentados como escolhidos de Deus pelas autoridades religiosas -, os liberais passaram a defender a separação entre política e religião e a não interferência de atores religiosos nas questões públicas. Transformações econômicas e sociopolíticas auxiliaram a causa liberal algumas vezes, como o desejo da Igreja de ter mais autonomia em relação aos monarcas e a Reforma Protestante, que colocou em xeque o seu poder, bem como a ascensão da classe burguesa que desejava a limitação do poder do rei para possuir maior liberdade em suas transações (Badie; Birnbaum, 1983).

Essas e outras transformações, aliadas à pressão liberal e à crescente insatisfação popular com os rumos políticos das sociedades europeias, acabaram culminando no rompimento do vínculo formal que existia entre o monarca e a Igreja, confinando atores políticos e religiosos em seus respectivos campos. A partir de então, não poderiam mais ser mobilizados argumentos como a aprovação divina para legitimar o poder do rei, e este também se tornou impossibilitado de vincular o Estado à Igreja, o que abriu o caminho para a instauração do princípio da laicidade estatal, que, posteriormente, foi desenvolvido para resultar na não proclamação de nenhuma religião oficial (Fleiner; Fleiner, 2009; Badie; Birnbaum, 1983). 
A separação entre Estado e religião já vinha sendo defendida desde o início da modernidade por autores soberanistas, como Maquiavel e Hobbes. Apesar de defender a ideia de um Estado absolutista, Hobbes pode ser considerado um precursor do pensamento político liberal devido ao individualismo e à autonomia da vontade que fundam sua teoria contratualista e, por consequência, sua defesa da separação entre a soberania do Estado (fruto de um contrato e de uma concessão livre e consciente do poder e da liberdade dos súditos ao soberano) e o poder e a moral religiosos (Bachur, 2006; Châtelet et al., 1990).

A mudança da concepção da fonte permanente da soberania (o povo ou a sociedade civil, que não abdica desse poder) e o imperativo de que o poder político fosse limitado em prol das liberdades e direitos individuais (concepção estranha a Hobbes) vão aparecer no impulso da Revolução Gloriosa na Inglaterra e com a obra de Locke. Segundo ele, a soberania popular deveria ser o fundamento do poder político, e era necessário que as leis fossem elaboradas em prol do bem público e aceitas pelo povo. Para tanto, também era preciso que existisse uma instância que legislasse segundo as leis estabelecidas e outra que as executassem, sem transferir ou compartilhar essas prerrogativas com nenhum outro tipo de ator e limitando o poder estatal dentro de suas próprias instituições (Châtelet et al., 1990; Várnagy, 2006).

Montesquieu, por sua vez, elaborou sua proposta de separação do poder estatal em diferentes instituições com base na premissa de que, assim como no campo físico, as leis políticas derivam da natureza das coisas, nesse caso da própria política. Para tanto, as instituições deveriam ser regidas por leis de natureza política, e não religiosa, o que resultou na seguinte proposta para conter a concentração de poder: estabelecer instâncias diferentes para elaborar leis (Legislativo), executá-las (Executivo) e verificar se as decisões tomadas são compatíveis com elas (Judiciário). Atuando de forma independente e contrabalanceada, cada uma dessas instâncias seria capaz de conter abusos por parte das outras, o que demonstra que, mais do que uma proposta puramente organizacional, Montesquieu propôs uma solução política para evitar o abuso do poder (Châtelet et al., 1990; Silva, 1969).

As propostas desses pensadores influenciaram diretamente a solução apresentada pelos federalistas para os Estados Unidos da América que desejavam instituir. Unindo a ideia da separação de poderes com a necessidade de se ter um Estado forte capaz de administrar um grande país, os federalistas adotaram a separação de poderes entre Legislativo, Executivo e Judiciário que se controlariam reciprocamente. Dessa forma, o poder do Estado era controlado em seu próprio âmbito, sem envolver atores não políticos nesse processo, que não poderiam representar os interesses do povo soberano (Hamilton; Jay; Madison, 1993).

Não havia, pois, espaço para a interferência de atores religiosos nesse novo arranjo político e organizacional, e os princípios racionais de administração e de legislação adquiriram maior força nesse processo. $O$ uso de normas religiosas na política foi substituído por leis adotadas por indivíduos e que não devem, a princípio, ficar sujeitas a vicissitudes políticas, personalistas ou religiosas. Consequentemente, a obediência a 
essas regras se dá por sua própria importância, não por uma característica sobrenatural, e, ademais, elas são aplicadas de forma universal entre os indivíduos por uma autoridade legalmente estabelecida, que deve sempre recorrer a esse conjunto estável de regras para tomar suas decisões. Dessa forma, também foi se consolidando a ideia de que quem deve legitimar o poder do governante é o próprio povo, e não mais as autoridades religiosas, abrindo o caminho para o reconhecimento da soberania popular que, para pensadores como Rousseau, constituía a liberdade do povo (Weber, 1999; Trubek, 2007).

Conforme é possível observar com essa exposição das características do modelo liberal, um de seus motes também era a defesa da igualdade entre os indivíduos. Foi a partir da Revolução Francesa que esse princípio passou a ser defendido para todas as pessoas, não havendo mais, portanto, a concessão de direitos aos indivíduos em função de sua classe social ou de sua confissão religiosa. Conforme a noção de igualdade ia se expandindo, as liberdades liberais - dentre elas a liberdade religiosa - foram sendo asseguradas a todas as pessoas sem garantir direitos específicos a nenhum grupo, já que passou a imperar a noção de que a igualdade e a liberdade não são privilégios de poucos, e o Estado deveria assegurar esse e outros direitos através da adoção de leis não discriminatórias e da garantia da participação popular, conforme defendido por Mill (Badie; Birnbaum, 1983).

Após essa breve apresentação das principais características da tradição islâmica e do modelo liberal, elas podem ser sintetizadas de forma comparada da seguinte maneira:

Quadro 1 - Comparação entre os princípios do modelo islâmico com os do modelo liberal

\begin{tabular}{|c|c|c|}
\cline { 2 - 4 } \multicolumn{1}{c|}{$\begin{array}{c}\text { Fundamentação do } \\
\text { poder e do Estado }\end{array}$} & Fodelo islâmico & Modelo liberal \\
\hline Relação entre Estado e religião & $\begin{array}{c}\text { Vínculo entre política e } \\
\text { religião, geralmente com } \\
\text { o reconhecimento do } \\
\text { Islã como religião oficial }\end{array}$ & Fundamentação laica \\
\hline Fontes do Direito & $\begin{array}{c}\text { Direito tradicional/ } \\
\text { sagrado }\end{array}$ & Estado laico \\
\hline $\begin{array}{c}\text { Reconhecimento da igualdade } \\
\text { e suas implicações para a } \\
\text { atribuição de direitos }\end{array}$ & $\begin{array}{c}\text { Direitos especiais e } \\
\text { de status pessoal para } \\
\text { grupos religiosos } \\
\text { específicos }\end{array}$ & Direito racional/legal \\
\hline
\end{tabular}

Fonte: Elaborado pelos autores, 2017.

Antes de analisar a convivência desses dois modelos nas Constituições do Egito, fazse necessário entender a maneira pela qual ela se tornou possível. O modelo liberal foi considerado pelos seus idealizadores e defensores como a melhor proposta de organização política não somente em suas próprias sociedades, mas também para regiões longínquas e com aspectos culturais, históricos e sociopolíticos muito diferentes dos da Europa do século XVIII. Essas diferenças não foram capazes de impedir a penetração do modelo 
liberal nesses locais, o que pode ser atribuído à força dos dois tipos de atores envolvidos no processo de sua adoção, a saber, os exportadores e os importadores (Badie, 2000).

No primeiro caso, os agentes exportadores eram europeus, principalmente britânicos e franceses, que desejavam disseminar o modelo político adotado em seus próprios países por crerem em sua efetividade, superioridade ou na facilidade que ele thes concederia para controlar a política nas sociedades receptoras devido à familiaridade que possuíam com seus princípios e seu funcionamento. Em se tratando dos agentes importadores, eles eram em sua maioria os próprios líderes políticos que desejavam obter do modelo liberal elementos que permitissem a consolidação de seu poder perante contestadores da ordem interna, como grupos religiosos ou tribais. Intelectuais, empreendedores, burocratas, funcionários de alto escalão e grupos minoritários também participavam desse processo, embora o papel de destaque na dinâmica da importação tenha sido desempenhado, de fato, pelos líderes políticos (Badie, 2000).

Houve muita resistência interna à incorporação de um modelo estrangeiro nos países que já possuíam tradições políticas próprias e coerentes com sua história e cultura e que passaram a experimentar dinâmicas políticas órfãs no início de tal incorporação devido à ruptura com a exclusividade de seus aspectos endógenos em sua administração. A escolha exclusiva entre modelo local e modelo exógeno não era possível devido à força que o processo de disseminação do liberalismo possuía principalmente se considerada a existência dos agentes importadores. Consequentemente, a solução encontrada foi a construção do que pode ser chamado de Estado híbrido, ou seja, um Estado que incorporou modelos estrangeiros em sua estrutura e que manteve em menor escala as suas próprias tradições políticas (Badie; Hermet, 1993).

Em termos práticos, a consequência da construção de Estados híbridos é a adoção de Constituições que conjugam elementos liberais com os tradicionais, o que resultou, muitas vezes, em textos constitucionais ambíguos e contraditórios. Entretanto, essas Constituições são capazes de se apresentarem como minimamente legítimas aos cidadãos dessas localidades, que conseguem identificar nelas elementos de sua própria cultura e história política ao lado de dispositivos constitucionais que refletem a incorporação do modelo liberal. Mesmo que esses textos constitucionais não sejam reconhecidos pela sua eficácia normativa devido à dificuldade que a acomodação entre elementos locais e estrangeiros apresenta para isso, eles ainda assim possuem relevância política e simbólica por serem considerados uma garantia do uso da tradição perante uma ordem política importada (Fleiner; Fleiner, 2009; Neves, 2011).

Ao longo do tempo, a conexão entre a ordem importada e a ordem tradicional passa por alterações, o que resulta no fortalecimento de uma em detrimento da outra, dinâmica que pode ser observada até a atualidade já que esse tipo de adaptação é constante. Ademais, a manipulação de elementos liberais ou tradicionais nos Estados híbridos pode atender a interesses políticos maiores do que a preocupação com a construção de uma ordem política pautada exclusivamente em um deles. A próxima seção desse artigo mostrará como o alcance de elementos liberais e islâmicos tem se alterado ao longo da trajetória 
constitucional do Egito, porque a dimensão religiosa foi reforçada na década de 1970 e qual foi o impacto disso sobre as Constituições adotadas em 2012 e 2014. Antes, porém, será brevemente apresentado o processo de disseminação do modelo liberal no país.

\section{Egito: um país entre princípios liberais e islâmicos}

O Egito não esteve imune ao processo de disseminação do modelo liberal pelo mundo, sendo possível observar estratégias de exportação e de importação no país. No primeiro caso, os antigos colonizadores britânicos foram os atores mais significativos, embora não se possa descartar a influência da França nesse processo. Entretanto, a presença francesa nessa dinâmica também pode ser atribuída às estratégias de importação empregadas no Egito, com destaque para os próprios líderes políticos do país que desejavam adotar do modelo liberal os elementos que permitissem a sua consolidação e, principalmente, a centralização do poder perante centros rivais (Badie; Hermet, 1993).

Esse esforço deve-se ao fato de que a história política egípcia é marcada pela presença da tradição islâmica e de sua dimensão política. Durante um longo tempo essa tradição foi utilizada para organizar as relações políticas no país, e, a partir da penetração do modelo liberal, o Egito passou por um processo de adaptação dessas duas propostas políticas distintas em sua estrutura administrativa. Renunciar à tradição islâmica em prol do modelo liberal sequer era uma alternativa dada a sua força interna e o seu uso por contestadores do poder do Estado, principalmente pelos movimentos islamistas que apresentavam suas propostas políticas em um discurso religioso capaz de ser compreendido pela população. Isso não ocorria com o modelo liberal e com seus elementos estranhos à tradição local, mas as vantagens administrativas que ele apresentava - principalmente aos olhos dos líderes políticos -, aliadas ao empenho dos exportadores de universalizar esse modelo europeu, impediram a sua marginalização nesse país do Oriente Médio (Fernandes, 2017; Badie; Hermet, 1993).

Ressaltar a dificuldade de compreensão do modelo liberal pela maioria dos egípcios não significa afirmar que não existiu nenhum movimento de natureza liberal no país até hoje. Como um resultado da própria dinâmica de exportação e importação, os princípios liberais tornaram-se elementos da própria ordem política egípcia - dentro das condições possíveis - e passaram a compor a agenda de alguns movimentos. Para além dos intelectuais e líderes políticos, alguns partidos também podem ser apresentados como liberais.

O principal deles foi o Partido Wafd, que foi a principal voz da oposição durante o período monárquico no Egito e que fez da necessidade de frear o poder do rei o seu principal mote. Outros partidos que foram criados - principalmente a partir da década de 1980, quando foi encerrado o regime de partido único, instituído em 1953 - muitas vezes assumiram nomes e propagaram discursos apenas rotulados como liberais. Mesmo aqueles que tentaram ser mais fiéis a uma agenda liberal não obtiveram muito êxito devido tanto ao autoritarismo estatal que busca cercear sua atuação - inclusive acusando- 
os de representarem os interesses ocidentais - quanto ao fato de serem reconhecidos como representantes das elites econômicas. Outros tipos de atores também podem ser apresentados como liberais, como organizações não governamentais, ativistas, associações, grupos formados por estudantes e movimentos que atuam em prol dos direitos humanos e que denunciam a violência estatal e o cerceamento da liberdade política no Egito (Makari, 2007; THE..., 2015; Mansour, 2016).

Deve-se, porém, fazer algumas observações a respeito da classificação desses atores como liberais. Em primeiro lugar, isso não significa que todos eles compartilham do conjunto dos princípios do liberalismo, uma vez que a incorporação da agenda liberal ocorreu com base no contexto egípcio, ou seja, ela foi influenciada e limitada pelos princípios políticos tradicionais do país. Também é preciso considerar que nem todo partido ou toda organização que se contrapõe ao regime egípcio é liberal. Classificálos dessa forma implica em desconsiderar o fato de que, para obter um espaço maior na política ou para promover alguma mudança que lhes seja mais favorável, esses atores estão dispostos a contrariarem os princípios mais caros ao liberalismo, conforme será melhor explicado na apresentação do cenário egípcio em 2013 (Hussain, 2014; Fernandes, 2017).

De todo modo, a alternativa encontrada para acomodar os elementos liberais e islâmicos na estrutura política do Egito foi conceder espaços para ambos em sua trajetória constitucional após a independência em 1922. Desde então, todas as Constituições que já vigoraram no país mantiveram essa dinâmica, conjugando elementos de modelos díspares e, consequentemente, apresentando um conteúdo marcado por contradições. Ao longo do tempo, é possível observar alterações no alcance concedido a cada um dos modelos, um resultado tanto da constante adaptação entre a ordem importada e a ordem tradicional quanto, principalmente, da manipulação de cada uma delas para atender a propósitos bem específicos (Fernandes, 2017).

Para entender os motivos por detrás de tal manipulação e os modos pelos quais a tradição islâmica foi reforçada nas Constituições do Egito, as próximas subseções apresentarão um panorama da interação entre elementos liberais e islâmicos nos documentos constitucionais adotados no período monárquico e no governo de Nasser, durante a liderança de Sadat, e, por fim, no governo de Mursi e no ano de 2014.

\subsection{Um breve histórico da trajetória constitucional do Egito de 1923 a 1964}

A primeira Constituição do Egito independente data do ano de 1923 e já proclamava que o Islã era a religião oficial do país, além de demonstrar o uso do direito religioso pelo aparato estatal ao estabelecer um ministério responsável por gerenciar doações feitas 
por muçulmanos em prol da religião ou da comunidade ${ }^{1}$ (Egito, 1923). Entretanto, essa presença da tradição islâmica nessa Constituição ocorreu não somente para atender às expectativas da sociedade egípcia sobre o lugar que a religião deveria ter na política, mas também como forma de definir e garantir a identidade do Egito tanto no âmbito interno quanto no externo.

A independência em relação à Grã-Bretanha não significou uma ruptura completa e imediata do Egito em relação à antiga metrópole. O governo britânico buscou assegurar sua influência sobre o país e, para tanto, tentou mobilizar a afiliação religiosa dos egípcios a seu favor. De acordo com eles, a Grã-Bretanha desejava segmentar o Egito em três diferentes grupos religiosos - muçulmanos, cristãos e judeus - com o intuito de facilitar o seu domínio sobre o país, o que seria possível pela criação de hostilidades entre eles. Para frustrar esse plano, os constituintes estabeleceram o Islã como a religião oficial com o intuito de afirmar que o Egito possuía uma identidade com um elemento religioso, o que o distinguia dos antigos colonizadores (Makari, 2007). Ademais, a religião islâmica concede direitos aos cristãos e judeus, e, por isso, seria o próprio aspecto da identidade nacional que garantiria a convivência pacífica entre as comunidades religiosas.

Elementos liberais, como soberania popular, separação de poderes e proclamação da igualdade e da liberdade também estiveram presentes na Constituição de 1923. A sua análise, entretanto, deve considerar, em se tratando principalmente da separação dos poderes, o autoritarismo que já caracterizava o Egito da época e que resultava na concentração do poder pelo monarca. Ademais, a liberdade de crença em conformidade com a tradição, a moral e a ordem pública assegurada pelo texto constitucional evidencia que a incorporação de elementos liberais, além de lidar com traços autoritários, também teve que se adequar à história do Egito,já que ela não garantia a liberdade de realizar rituais religiosos em público para seguidores de religiões diferentes do Islã, do Cristianismo e do Judaísmo (Egito, 1923; Scott, 2010).

A Constituição monárquica vigorou por 24 anos e foi suspensa após o golpe militar orquestrado pelo Clube dos Oficiais Livres em 1952, que depôs o rei e estabeleceu uma junta militar para governar o Egito durante o período de transição. ${ }^{2}$ A Declaração Constitucional de 1953 emitida pela junta demonstra que, se a oposição ao rei era uma pauta comum entre os militares, os rumos que o Egito deveria tomar após sua deposição

1 Essas doações são realizadas para atender aos propósitos da caridade pregados pelo Islã, embora em alguns casos elas sirvam para manter propriedades na família. As doações devem ser regulamentadas por um contrato cuja assinatura envolve uma terceira parte para além de doador e receptor. Para atender a esse objetivo e regular as doações, o Egito estabeleceu o Ministério das Doações Religiosas (Fernandes, 2017).

2 Em 1930, o rei outorgou uma nova Constituição que se distinguia da anterior pela maior concentração de poder em suas mãos e pelo estabelecimento de critérios censitários para a candidatura e o voto. A liberdade de crença foi eliminada, o que pode ser entendido tanto em relação ao autoritarismo quanto ao desejo do monarca de obter o apoio dos líderes religiosos que não desejavam estender esse direito indiscriminadamente. A rejeição popular pela nova Carta inviabilizou a sua vigência, sendo substituída pela Constituição de 1923 cinco anos depois (Egito, 1930; Makari, 2007). 
eram disputados entre eles, razão pela qual seu conteúdo é bastante sucinto e sequer estabelece o tipo de regime que estava em vigor naquele momento (Vatikiotis, 1985; Egito, 1953).

Se essa declaração não traz informações relevantes para a análise do cenário político do Egito na época, e tampouco sobre a coexistência entre elementos liberais e islâmicos, o mesmo não se pode afirmar sobre a Constituição de 1956. O novo texto constitucional inaugurou o regime republicano e o sistema presidencialista no Egito, mas também trouxe algumas modificações em relação ao alcance da dimensão religiosa. A proclamação do Islã como religião oficial foi trazida para o artigo $3^{\circ}$, na seção $O$ Estado egípcio, em substituição à sua alocação no final do texto da Constituição de 1923 junto com assuntos tratados como disposições gerais. Ademais, a religião foi considerada um elemento definidor da família egípcia ao lado do patriotismo e da moralidade no artigo $6^{\circ}$ (Egito, 1956).

Pouco tempo após a adoção da Constituição de 1956, Gamal Abdel Nasser foi eleito presidente da República em um referendo popular. Antes disso, ele já era uma das maiores lideranças políticas do Egito, o que torna difícil descartar a sua influência na redação do referido documento constitucional. Embora Nasser seja reconhecido como um líder de orientação laica, ele não pôde descartar a herança religiosa do Egito que já se expressava constitucionalmente quando chegou ao poder. A alternativa encontrada pelo antigo mandatário foi mobilizá-la a seu favor, criando um processo de estatização da religião no país que consistia em trazer para o controle estatal instituições religiosas, o que é exemplificado pela nacionalização de Al-Azhar e pelo uso de normas religiosas pelo poder Judiciário para resolver disputas familiares de cristãos e judeus após a abolição das cortes religiosas pelo próprio Nasser (Esposito, 1998; Makari, 2007; Tadros, 2013).

Para justificar suas decisões políticas, Nasser muitas vezes recorria aos clérigos de Al-Azhar e solicitava-lhes fatwas $^{3}$ que as corroborassem. O presidente egípcio também manteve uma relação próxima com Cirilo VI, patriarca da Igreja Copta Ortodoxa na época, como forma de angariar o apoio dos cristãos coptas ao regime, apesar de sua delicada situação política e econômica naquele período. Essa interação com instituições religiosas, aliada às alterações na Constituição de 1956 que foram mencionadas, permitiam com que Nasser mobilizasse sua suposta abertura e tolerância à presença da tradição islâmica na política do Egito para se assegurar no poder, o que era vantajoso não somente para sua legitimidade perante a sociedade egípcia como um todo, mas também para fazer frente à Irmandade Muçulmana (IM) - e a outros movimentos islamistas -, que usava um discurso religioso para se contrapor ao Estado e que possuía uma agenda política própria, nesse momento baseada na ideia de substituir o aparato estatal egípcio por uma forma de governança coerente apenas com os princípios islâmicos (Esposito, 1998; Tadros, 2013).

A tentativa de Nasser de enfraquecer a IM deu início à histórica relação conflituosa entre a cúpula das Forças Armadas do Egito e a organização, embora outros movimentos

3 Fatwas são pronunciamentos legais islâmicos realizados por um especialista na lei islâmica e que se aplica apenas para o caso específico apresentado para interpretação. Sua emissão não implica na obrigatoriedade de seu cumprimento. 
islamistas também tenham sido perseguidos. O antigo mandatário conhecia a força da IM, que, além de prestar serviços básicos para a população por todo o país, propagava um discurso que, se bem que nem sempre amplamente aceito, era compreendido pela maioria dos egípcios. Portanto, para disseminar uma narrativa religiosa que lhe favorecesse, Nasser desencadeou uma perseguição à IM, acusando-a de defender ideias radicais, o que resultou na prisão de muitos dos seus membros. Embora esse tipo de perseguição tenha ocorrido com todos os que eram vistos como ameaças por Nasser, a tentativa de retirar a organização da cena política foi a mais enfática já que ela era a única com o potencial de formar uma opinião nacional contrária ao presidente (Fernandes, 2017).

Elementos liberais também estão presentes na Constituição de 1956 e podem ser encontrados na proclamação da soberania popular, na separação de poderes e na garantia da igualdade e da liberdade nos mesmos termos do texto constitucional de 1923 (Egito, 1956). Novamente, é preciso atentar para o fato de que o que se observa nesse caso é a incorporação de princípios provenientes do modelo liberal, e não a sua adoção da maneira exata estipulada por seus idealizadores, o que é um resultado tanto do autoritarismo do Egito quanto da necessidade de adequar a sua incorporação à tradição local, o que é verificado por restrições à liberdade religiosa não por um puro preconceito, mas para atender a uma coerência própria do modelo religioso em vigor no país.

Outros dois documentos constitucionais vigoraram enquanto Nasser presidiu o Egito. O primeiro foi a Constituição provisória adotada em 1958 e que instituía a República Árabe Unida (RAU), país fundado a partir da união entre Egito e Síria. Não há elementos da tradição islâmica nessa Constituição, e os elementos liberais também foram modificados em seu silêncio sobre o direito à liberdade religiosa e de realizar ritos religiosos. Porém, essa Constituição foi adotada em caráter provisório e, portanto, não é possível encontrar em seu texto prescrições específicas para o conjunto de questões sobre o novo país que ela instituía (REPÚBLICA ÁRABE UNIDA, 1958).

O segundo documento constitucional entrou em vigor em 1964, três anos após o fim da RAU, e instituiu o regime socialista no Egito, embora políticas econômicas dessa natureza fossem adotadas no país há algum tempo. A alteração que pode ser mencionada é o retorno da liberdade de crença nos mesmos termos das Constituições anteriores, não sendo modificadas as demais disposições (REPÚBLICA ÁRABE UNIDA, 1964). O que chama a atenção é a manutenção da presença religiosa em uma Constituição socialista, o que foi realizado para permitir que Nasser continuasse mobilizando argumentos religiosos para justificar suas decisões políticas. Ademais, a Constituição de 1964, bem como as outras que vigoraram durante o governo do antigo mandatário, evidencia que a condição para a cessão de um espaço para a dimensão religiosa era o seu controle pelo Estado, o que permitia a sua manipulação para atender a objetivos políticos.

Percebe-se, portanto, que a dimensão religiosa possui uma considerável força na política do Egito e que ela se expande ao longo do tempo, ao menos nos textos constitucionais. A incorporação dos elementos liberais não descarta a sua própria sintonia com a tradição islâmica, e existem disputas entre atores de diferentes naturezas no Egito 
em relação ao alcance que cada modelo político terá na ocasião da adoção de uma nova Constituição. Isso porque os aparatos político e religioso se relacionam no país, em alguns casos se confluem, e alterações no espaço destinado a elementos religiosos podem modificar esse quadro, desencadeando disputas de poder. As subseções seguintes, que abordarão a expansão do alcance da dimensão religiosa nas Constituições de 1971, 2012 e 2014, mostrarão essas questões de maneira mais aprofundada.

\subsection{O governo de Sadat e a Constituição de 1971}

Com a morte de Nasser em 1970, o seu vice-presidente e também militar, Anwar al-Sadat, assumiu a presidência do Egito. O novo presidente, entretanto, possuía planos diferentes para o país: diante de um quadro econômico delicado que o Egito vivenciava desde a derrota para Israel na Guerra dos Seis Dias, Sadat buscou tornar a economia egípcia atrativa para os investidores internacionais ocidentais, que haviam se retirado de vez do país com a institucionalização do regime socialista em 1964. Para tanto, sua alternativa foi liberalizar gradativamente a economia do Egito, o que também resultou na maior presença de elementos liberais na nova Constituição, que passou a vigorar em 1971. A interferência do Estado sobre a vida e sobre a propriedade dos indivíduos foi restringida com a afirmação da liberdade individual como um direito natural, e também houve reformas na separação dos poderes no Egito - com destaque para a afirmação de que uma Suprema Corte Constitucional (SCC) seria instituída - que permitiram uma maior estabilidade institucional em detrimento da vontade do chefe do Executivo (Esposito, 1998; Egito, 1971).

Essa abertura do Egito ao Ocidente, entretanto, foi criticada pelos apoiadores de Nasser que a consideraram como um abandono das políticas adotadas pelo antigo presidente e que trouxeram avanços socioeconômicos para o país. Ciente de que essa oposição existiria, Sadat buscou o apoio dos movimentos islamistas, antigos rivais de Nasser, como forma de diminuir o impacto das críticas ao seu governo. Nesse momento, a IM ressurgiu com força revigorada e com uma nova postura: os anos de perseguição durante o governo de Nasser foram fundamentais para uma mudança na organização, que passou a adotar um discurso mais moderado - afirmando agora seu desejo de conquistar o Estado para transformá-lo a partir de dentro - e a ser reconhecida pela população como uma alternativa viável entre o regime militar e os islamistas radicais (Esposito, 1998).

Para obter esse apoio dos islamistas, inclusive da própria IM, Sadat teve que atender a uma antiga reivindicação desses movimentos e concedeu maior espaço para a tradição islâmica na política do Egito, inclusive na nova Constituição. A partir de então, o reconhecimento do Islã como religião oficial, no artigo $2^{\circ}$, passou a ser acompanhado do comprometimento estatal em promover a tradição religiosa, e não apenas reconhecê-la, 
o que é exemplificado por artigos ${ }^{4}$ que atribuíam funções específicas ao Estado a fim de que pudesse executar essa tarefa (Esposito, 1998; Egito, 1971).

Entretanto, a principal modificação na Constituição de 1971 foi a afirmação de que os princípios da Shari'a seriam considerados uma das principais fontes de legislação no Egito, o que rompia o espaço conferido até então à tradição islâmica na trajetória constitucional do país, expandindo-o consideravelmente. É preciso destacar, entretanto, que não foi especificado no texto constitucional a maneira pela qual tais princípios seriam incorporados no aparato legal do Egito (Egito, 1971; Scott, 2010).

Ficou claro, a partir disso, que o aumento do alcance da dimensão religiosa foi realizado para que Sadat obtivesse o apoio dos islamistas e, de forma geral, apaziguasse os ânimos da sociedade perante as transformações que desejava implementar no Egito. Ao perceberem isso, os movimentos islamistas passaram a criticar a falsa piedade islâmica do presidente, endossando a crítica daqueles que se opunham à abertura da economia egípcia ao Ocidente e, principalmente, à assinatura dos acordos de Camp David (Esposito, 1998).

Para tentar reverter esse cenário, Sadat buscou novamente manipular o alcance da dimensão religiosa na Constituição de 1971. Em 1980, foi aprovada em um referendo a sua proposta de emenda à Constituição que modificou o texto constitucional para afirmar que os princípios da Shari'a seriam a principal fonte de legislação. Apesar de também ser pouco específica, Sadat considerou essa modificação como capaz de apaziguar os ânimos dos islamistas e de garantir o seu poder perante a sua oposição e também perante outros atores. Essa mesma emenda constitucional consagrou o retorno ao sistema multipartidário e a possibilidade ilimitada de reeleição para a presidência da República. Em outras palavras, Sadat mobilizou o apelo que a alteração proposta sobre o uso da Shari'a teria socialmente, assim como o forte desejo interno de acabar com o regime de partido único que vigorava desde 1953, para perpetuar-se no poder mesmo perante a contestação interna (Egito, 1980; Esposito, 1998).

Essa tentativa de Sadat de manipular os movimentos islamistas não alcançou todos os efeitos desejados. Mesmo com a alteração da Constituição em 1981, a oposição de tais movimentos ao presidente aumentou, e eles passaram a afirmar que Sadat usava o discurso religioso em benefício próprio e afastava o Egito daquilo que era idealizado pela tradição política islâmica, opinião que passou a ser compartilhada entre muitos egípcios. A tensão nesse sentido chegou a tal ponto que, também em 1981, Sadat foi assassinado durante um desfile militar, o que foi atribuído ao grupo islamista Sociedade da Guerra Santa (Esposito, 1998).

4 Caberia ao Estado preservar o caráter autêntico da família egípcia construída sobre a religião, a moral e o patriotismo e desenvolvê-lo nas relações da sociedade (artigo $9^{\circ}$ ); coordenar as obrigações das mulheres em relação à sua família e ao seu trabalho e não permitir que a sua igualdade perante os homens contrariasse as regras da jurisprudência islâmica (artigo $11^{\circ}$ ); e garantir o ensino da educação religiosa nos cursos de educação geral (artigo $\left.19^{\circ}\right)$. 
O que deve ser destacado é que a Constituição de 1971 é o exemplo mais contundente do tipo de manipulação das dimensões islâmica e liberal que ocorre no Egito. Isso porque, em comparação com os documentos constitucionais anteriores, ela foi a primeira que avançou em direção a ambas as dimensões ao introduzir significativos artigos de natureza religiosa ao mesmo tempo em que buscava assegurar a liberdade e a estabilidade tais como entendidas pelo modelo liberal (Fernandes, 2017). Esses avanços, por outro lado, não transformaram o Egito em um Estado religioso e tampouco liberal, já que houve limitações na adoção dos artigos de conteúdo religioso - como a sua falta de especificidade e a não incorporação de todos os assuntos que poderiam ser regidos pela Shari'a - e os inspirados no modelo liberal, conforme o autoritarismo e os escassos direitos assegurados evidenciam.

Outro exemplo desse tipo de manipulação do texto constitucional na Carta de 1971 ocorreu com o sucessor de Sadat, o também militar Hosni Mubarak. Em 2007, uma emenda constitucional proposta pelo então presidente foi aprovada, o que resultou na eliminação de elementos socialistas de seu texto que ainda existiam e na proibição da formação de partidos políticos e da realização de qualquer atividade política com base em um quadro religioso, de gênero e de origem assegurada no artigo $5^{\circ}$. $\mathrm{Na}$ prática, isso resultava na restrição do uso de critérios religiosos para a composição do governo, o que implicava em uma separação entre política e religião nesse sentido (Egito, 2007; BernardMaugirou, 2008).

Essa modificação da Constituição de 1971 foi adotada para proibir as diversas formas de participação política de movimentos islamistas, já que essa proibição se aplicava à realização de qualquer atividade, o que poderia incluir até protestos organizados por eles. Ciente do tipo de reação que essa alteração poderia gerar, Mubarak afirmou que não desejava laicizar o Egito, mas impedir a manifestação de preconceitos religiosos na política (Bernard-Maugirou, 2008). Era preferível, portanto, arriscar a sua imagem ao alterar a delicada coexistência entre elementos liberais e islâmicos se isso enfraquecesse o poder político dos movimentos islamistas, principalmente da IM, que, após o assassinato de Sadat, ganhou ainda mais força como uma alternativa política viável no Egito. A alta cúpula das Forças Armadas sabia que, se houvesse uma democratização no país, a organização seria a grande vitoriosa.

\subsection{Ascensão e queda da Irmandade Muçulmana: as Constituições de 2012 e de 2014}

Em 2011, Mubarak renunciou à presidência do Egito após manifestações na Praça Tahrir que instituíram o capítulo egípcio da história dos levantes árabes daquele ano. Embora os manifestantes pedissem pelo fim do autoritarismo do Estado, deve-se tomar cuidado com a classificação desses protestos como liberais. Em primeiro lugar, grupos muito distintos participaram deles, o que torna inviável igualar todas as suas demandas em 
um único conjunto de propostas liberais. Por outro lado, os motes das manifestações eram "O povo exige a queda do regime" e "Pão, liberdade e justiça social", o que não permite enquadrá-las unicamente como liberais, mas sim como o desejo de abrir a caixa-preta do Estado e exigir o atendimento de necessidades básicas. Se essas questões podem ser classificadas como liberais, outras que também podem, como a separação entre religião e Estado, não foram ouvidas na Praça Tahrir em 2011 (Brancoli, 2013).

Mesmo assim, a alteração do alcance das dimensões liberal e islâmica também ocorreu nas transformações constitucionais vivenciadas pelo Egito após a renúncia de Mubarak em 2011, mesmo ano no qual foi emitida pelo Supremo Conselho das Forças Armadas (SCFA) - responsável pelo período de transição - uma Declaração Constitucional, que estipulou os detalhes das eleições legislativas que deveriam ser realizadas para formar um novo parlamento. A IM foi a grande vitoriosa nessas eleições com os votos atribuídos ao seu recém-criado Partido Liberdade e Justiça e, coligando-se com outros partidos islamistas, compôs a maioria do Poder Legislativo do Egito. Já em 2012, as eleições presidenciais elegeram Muhammad Mursi, membro da organização, como o presidente do país. A vitória expressiva da IM é a prova de que os temores dos militares sobre sua força política não eram infundados, razão pela qual buscaram sempre coibir sua atuação política (Moustafa, 2012).

O histórico de atuação e de organização da IM colocou-a em vantagem em comparação com outros movimentos que não conseguiram resistir da mesma forma ao autoritarismo do Egito. Ademais, perante candidatos e partidos que ou representavam a velha ordem política ou eram radicais, a IM foi capaz de se apresentar como uma alternativa viável e moderada para aquele momento. Apesar disso, sua proposta política nunca foi apresentada de forma clara aos egípcios, mas o que se sabia era que a organização desejava expandir o alcance da tradição islâmica na política (Moustafa, 2012; Stilt, 2010).

A grande representação da IM no Legislativo, bem como a eleição de Mursi, garantiram a presença esmagadora de islamistas na Assembleia Constituinte, ocasião aproveitada por eles para transformar o aparato estatal egípcio a partir de uma base religiosa, e o choque entre islamistas e liberais nesse momento foi muito mais significativo do que durante as manifestações de 2011. O resultado dessa transformação foi a inclusão, na Carta de 2012, da obrigatoriedade do ensino da educação religiosa até os cursos pré-universitários; do direito ao desenvolvimento religioso para as crianças; da proibição do insulto a profetas e mensageiros religiosos; e da obrigação do Estado de promover o sistema de doações religiosas, e não apenas regulá-lo (Egito, 2012).

O impacto dessas alterações, entretanto, foi bem menor do que outras trazidas pela nova Constituição. $\mathrm{O}$ artigo $4^{\circ}$ e o 219 especificaram pela primeira vez o uso do direito religioso pelo Estado. No primeiro, foi assegurada a independência de Al-Azhar e também a garantia de que os seus especialistas seriam consultados nas questões relacionadas à lei islâmica. Essa alteração atendia ao desejo da IM de ver as instituições religiosas do Egito operando de forma autônoma e compromissada com sua missão espiritual e não mais subservientes ao Estado em troca de recursos. Apesar disso, o artigo $4^{\circ}$ retirava da SCC 
a exclusividade na interpretação da constitucionalidade das leis no Egito, mas a IM não considerou isso como algo problemático já que, em sua visão, os juízes leigos da corte não eram os mais apropriados para interpretarem a lei islâmica (Egito, 2012; Stilt, 2010).

Já o artigo 219 estipulou que a doutrina sunita seria a utilizada para definir e interpretar os princípios da Shari'a, considerados a principal fonte de legislação e que deveriam incluir evidência geral, regras fundacionais, regras de jurisprudência e fontes aceitas no âmbito das tradições sunitas ou pela comunidade maior. Na prática, o artigo 219 definia o que deveria ser considerado como princípios da Shari'a pela SCC, diminuindo ainda mais a sua autonomia nesse assunto (Egito, 2012).

A próxima alteração da Constituição de 2012 ocorreu em relação à dimensão liberal, mais especificamente no que se refere à igualdade e à liberdade religiosa. A garantia da igualdade a despeito das diferenças foi eliminada, assim como os critérios para impedir a prisão arbitrária, e a liberdade religiosa foi considerada um direito inviolável, mas não natural. Na visão da IM, os egípcios eram diferentes entre si por pertencerem a comunidades religiosas distintas, mas isso parece ter se desdobrado em problemas para a garantia de direitos entre eles. Por outro lado, essas alterações devem ser consideradas do ponto de vista da proposta de acomodação de minorias religiosas idealizada pela organização, o que ajuda também a entender a introdução, apesar das alterações mencionadas, do direito de cristãos e judeus de praticarem ritos religiosos e de estabelecerem seus locais de culto, bem como de utilizarem seus respectivos princípios canônicos para resolverem questões de status pessoal, assuntos religiosos e para escolherem seus líderes espirituais, conforme assegurado no artigo $3^{\circ}$ (Egito, 2012; Stilt, 2010).

As turbulências políticas vivenciadas pelo Egito durante o governo de Mursi logo fizeram com que o presidente fosse deposto um ano após a sua eleição por um golpe militar e que a Constituição de 2012 fosse suspensa. Perante a incapacidade administrativa de Mursi, a alta cúpula militar do Egito tomou o poder em um golpe de Estado, o que gerou a impressão de que os militares utilizaram as manifestações de 2011 para se livrarem de Mubarak - com o qual já apresentavam discordâncias quanto à sucessão presidencial - e, posteriormente, se aproveitaram das inabilidades de Mursi e das próprias dificuldades que um governo civil eleito teria em um país de trajetória política militar e autoritária para retornarem ao poder apresentando-se como protetores da revolução. A partir de então, a IM passou a vivenciar um novo período de perseguição, o que se estende até o momento. Declarada uma organização terrorista em 2013, seus membros ou estão encarcerados - como o próprio Mursi - ou agem na clandestinidade, porém com menor força do que antes (Salhi, 2016).

Muitos atores tidos como liberais no Egito apoiaram a destituição de Mursi, tendo em vista a sua forte oposição aos islamistas. Portanto, para se livrar de um governo que não lhes concedia participação, esses atores liberais estavam dispostos a apoiar uma mudança política que ameaçava a soberania popular e os direitos políticos dos egípcios. Por isso, nem toda manifestação popular pode ser considerada liberal no Egito, seja contra o regime militar ou o governo islamista (Hussain, 2014). 
Em 2013, uma Declaração Constitucional foi adotada para vigorar até a elaboração de uma Constituição permanente e também para delimitar o seu processo de redação. $O$ que chama a atenção nessa declaração, entretanto, é a manipulação da dimensão liberal para conferir mais legitimidade a um processo de transição política de legalidade questionável. A igualdade apesar das diferenças foi restabelecida, a liberdade individual passou a ser garantida nos mesmos termos da Constituição de 1971, e a liberdade de crença e de praticar ritos religiosos não foi designada para comunidades religiosas específicas. A leitura desses artigos demonstra uma tentativa de reverter as modificações introduzidas pelos islamistas na Constituição de 2012 e, principalmente, de conferir um aspecto inclusivo ao processo de transição que fosse capaz de lhe atribuir legitimidade interna e internacional (Al-Ali, 2013; Egito, 2013).

Foi também para atender a esses propósitos que a referida declaração garantiu a participação de vários segmentos sociais na Assembleia Constituinte, responsável por redigir a Constituição permanente, tendo a cautela de assegurar que somente os opositores dos islamistas seriam escolhidos dentre eles. Consequentemente, a nova Constituição, adotada em 2014, eliminou a maioria do alcance do uso da tradição religiosa na política trazido pelos islamistas, retornando ao status quo de 1971 no que se refere à relação entre política e religião no Egito. Esse retorno assegurou a autonomia da SCC em relação à interferência de atores religiosos em sua interpretação da adequação das leis do Egito à Shari'a, o que é um exemplo do processo de estatização da religião no Egito, e não da sua laicização (Egito, 2013; Egito, 2014; Moustafa, 2016).

A proibição de insultar mensageiros e profetas também foi eliminada na nova Constituição, que tornou a proibir partidos e atividades políticas organizados em bases religiosas ${ }^{5}$.A retração da dimensão religiosa-islâmica na Constituição de 2014 não ocorreu, portanto, devido a uma agenda política dos constituintes, mas sim pelo seu interesse em eliminar o legado dos islamistas da política do Egito, principalmente o da IM, que se opuseram à destituição de Mursi. Essas alterações não foram, portanto, um primeiro passo em direção a uma laicização, mas sim um retorno ao histórico relacionamento entre Estado e religião no qual aquele garante um espaço para a dimensão religiosa na política desde que possa controlar o tipo de discurso religioso que é propagado (Egito, 2014; Fernandes, 2017).

Por fim, em 2014, critérios como raça, cor, idioma, deficiência, classe social e afiliação política foram considerados como diferenciadores dos indivíduos, e o Estado se comprometeu a combater diretamente a discriminação. A liberdade de crença passou a ser considerada um direito absoluto no Egito, mas a liberdade de praticar rituais religiosos e de estabelecer locais de adoração voltou a ser restrita aos cristãos, judeus e muçulmanos. $\mathrm{O}$ artigo $3^{\circ}$ da Constituição de 2012 foi mantido sem alterações, e os artigos 180 e 244 asseguraram o direito à representação política dos cristãos, bem como de mulheres e deficientes. $\mathrm{O}$ esforço de assegurar uma adequada representação da pluralidade social do

5 Essa proibição havia sido alterada em 2012 para garantir que apenas os partidos que discriminassem em bases religiosas estariam proibidos. 
Egito após o golpe militar, para conferir mais legitimidade à transformação política por ele desencadeada foi, portanto, aproveitado por grupos para assegurar alguns direitos almejados há tempos e eliminar a desigualdade que muitas vezes dificultava sua participação política, o que era o caso dos cristãos. Os avanços liberais em 2014 ficaram, dessa forma, restritos à garantia de apenas alguns direitos para grupos específicos (Egito, 2014; Fernandes, 2017).

As modificações nas dimensões liberal e islâmica do Egito na Constituição de 2014 não resultam de uma democratização do país e da tentativa de implementar uma agenda política bem definida. Ao contrário, elas resultam de uma situação política que permitiu a representação de grupos rivais dos islamistas que forneceriam legitimidade na medida em que conseguissem garantir alguns direitos específicos. Outras questões, como o autoritarismo e o grande poder dos militares, foram mantidas na nova Constituição, que vigora até o momento, o que demonstra que, para retornar ao status quo anterior à ascensão da IM, as principais forças políticas do Egito estavam dispostas a conceder beneficios a certos grupos, mas desde que eles não confundissem isso com o início de um processo transformador da política do país.

\section{Considerações finais}

O aspecto híbrido do Egito fica evidente na constatação de elementos liberais e islâmicos a partir da leitura de suas Constituições.Também é possível observar uma interação entre ambos que cria uma conexão entre a ordem importada e a ordem tradicional que é o próprio fundamento do Estado-nação egípcio, como o uso do direito religioso pelo aparato estatal organizado nos moldes liberais exemplifica. O que essa observação permite afirmar é que os princípios do modelo liberal constituem, hoje, elementos da própria ordem política do Egito, fazendo com que a existência e o aumento do alcance do espaço religioso no país ocorram no âmbito de instituições liberais, e não em detrimento delas.

O papel que os líderes políticos do Egito desempenham na incorporação do modelo liberal e na sua acomodação com a tradição islâmica é de grande destaque. A concentração de poder pelo chefe do Executivo lhes concede essa oportunidade, e, com isso, interesses políticos e econômicos são buscados mais do que a implementação de uma agenda liberal ou islâmica. A exceção é a Constituição de 2012 cujas alterações nesta última dimensão refletiam, de fato, a agenda político-religiosa da IM, o que foi inédito na trajetória constitucional do Egito e permanece sendo o único caso que pode ser classificado dessa forma.

Por outro lado, mesmo nas demais Constituições, observa-se que a adoção da tradição islâmica ocupa um espaço mais do que simbólico no Egito, principalmente a partir de 1971. Isso leva à observação de que todos os atores políticos do Egito possuem uma agenda religiosa, mesmo que nem todos desejem expandir a presença da religião no sistema político, e o que é disputado entre eles é o espaço concedido à religião em suas respectivas agendas. É claro que também existem disputas em torno de uma 
agenda liberal, mas deve-se destacar que o tamanho do espaço concedido a elementos liberais ou islâmicos no país é o resultado de uma estratégia de suas lideranças políticas que introduzem princípios de tais modelos nas Constituições para atender a objetivos específicos - exceto em 2012 -, e a Constituição de 1971 exemplifica isso.

A leitura de seu texto demonstra uma expansão de direitos liberais e de elementos da tradição islâmica, o que leva à constatação de que a ampliação de um modelo não necessariamente demanda a retração do outro. Isso também é corroborado pelo fato de que as próprias modificações nessa convivência entre elementos liberais e islâmicos eram pontuais e não desencadeavam mudanças maiores, o que é exemplificado pelo fato de que, apesar da Shari'a ser considerada fonte de legislação desde 1971, os direitos especiais de cristãos e judeus por ela assegurados só foram adotados na Constituição de 2012.

Destarte, a condição para a presença da tradição islâmica na política do Egito e para sua convivência com elementos liberais é o seu controle pelo Estado, e essa estatização da religião faz com que o discurso religioso do país o favoreça. Portanto, o espaço da religião na política e a sua acomodação com o modelo liberal no Egito deve ser entendido como um quadro complexo no qual diferentes atores disputam o poder.É com essa perspectiva que a trajetória constitucional do país deve ser analisada, bem como possíveis mudanças em tal quadro que podem vir a ocorrer.

\section{Referências}

AL-ALI, Zaid. Another Egyptian constitutional declaration. POMEPS Briefings: Egypt's Political Reset, 23 jul. 2013. Disponível em: <http://pomeps.org/wp-content/uploads/2013/07/POMEPS_BriefBooklet20_Egypt_ web.pdf>. Acesso em: 15 nov. 2016.

AL-ASHMAWY, Muhammad Said. Islam and the political order. Washington, D.C.: Council for Research in Values and Philosophy, 1994.

BACHUR, João Paulo. Individualismo, liberalismo e filosofia da história. Lua Nova, n. 66, p. 167-203, 2006.

BADIE, Bertrand. The Imported State: The Westernization of the Political Order. Tradução de Claudia Royal. Stanford: Stanford University Press, 2000.

BADIE, Bertrand; BIRNBAUM, Pierre. State, Society and History. In: BADIE, Bertrand; BIRNBAUM, Pierre. The Sociology of the State. Tradução de Arthur Goldhammer. Chicago: The University of Chicago Press, 1983. cap. 2. p. 65-102.

BADIE, Bertrand; HERMET, Guy. Política Comparada. Cidade do México: Fondo de Cultura Económica, 1993.

BERNARD-MAUGIROU, Nathalie. The 2007 Constitutional Amendments in Egypt, and Their Implications on the Balance of Power. Arab Law Quaterly, v. 22, n. 4, p. 397-417, 2008. Disponível em: <http://www.jstor.org/ stable/27650634>. Acesso em: 20 nov. 2016.

BRANCOLI, Fernando. Primavera Árabe: praças, ruas e revoltas. São Paulo: Desatino, 2013.

CHÂTELET, François; DUHAMEL, Olivier; PISIER-KOUCHNER, Evelyne. História das Idéias Políticas. 2. ed. Rio de Janeiro: Zahar, 1990.

EGITO. Constituição. Constitution of the Republic of Egypt. Cairo, 1956. Constituição. Constitution of the Arab Republic of Egypt. Cairo, 2014. Constituição. Egyptian Royal Rescript promulgating a New Constitution. Cairo, 1930. 
1923.

Constituição. Royal Decree N 42 of 1923 On Building a Constitutional System for the Egyptian State. Cairo,

Constituição. The Constitution of the Arab Republic of Egypt. Cairo, 1971.

Constituição. The Constitution of the Arab Republic of Egypt (last amended 1980). Cairo, 1980.

. Constituição. The Constitution of the Arab Republic of Egypt (as amended to 2007). Cairo, 2007.

Constituição. The Constitution of the Arab Republic of Egypt. Cairo, 2012.

Declaração Constitucional. Constitutional Declaration. Cairo, 2013.

Declaração Constitucional. Provisional Constitution. Cairo, 1953.

ESPOSITO, John L. Islam and Politics. 4. ed. Syracuse: Syracuse University Press, 1998.

FERNANDES, Márcia de Paiva. RELIGIÃO, POLÍTICA E DIREITOS DE MINORIAS: um estudo das Constituições egípcias (1923-2014). 2017. 130f. Dissertação (Mestrado em Ciência Política) - Universidade Estadual de Campinas, Campinas, SP, 2017.

FLEINER, Thomas; FLEINER, Lidija R. Basta. Constitutional Democracy in a Multicultural and Globalised World. Heidelberg: Springer, 2009.

HAMILTON, Alexander; JAY, John; MADISON, James. Os artigos federalistas, 1787-1788. Tradução de Maria Luiza X. de A. Borges. Rio de Janeiro: Nova Fronteira, 1993.

HUSSAIN, Faheem A. Egypt's liberal coup? Open Democracy, 13 ago. 2014. Disponível em: <https://www.opendemocracy. net/north-africa-west-asia/faheem-hussain/egypt\%27s-liberal-coup>. Acesso em: 22 abr. 2018.

MAKARI, Peter E. Conflict \& Cooperation: Christian-Muslim Relations in Contemporary Egypt. Syracuse: Syracuse University Press, 2007.

MANSOUR, Muhammad.Why Sisi Fears Egypt's Liberals. Foreign Affairs, 2016. Disponível em: < https://www.foreignaffairs. com/articles/egypt/2016-05-18/why-sisi-fears-egypts-liberals>. Acesso em: 22 abr. 2018.

MOUSTAFA, Tamir. Drafting Egypt's Constitution: Can a New Legal Framework Revive A Flawed Transition? Brookings Doha Center, n. 1, 2012. Disponível em: <https://www.brookings.edu/wp-content/uploads/2016/06/new1-DraftingEgypts-New-ConstitutionEnR03.pdf>. Acesso em: 15 nov. 2016.

NAZIR-ALI, Michael. Islamic Law, Fundamental Freedoms, and Social Cohesion: Retrospect and Prospect. In: AHDAR, Rex; ARONEY, Nicholas (Ed.). Shari'a in the West. Oxford: Oxford University Press, 2010. cap. 5. p. 71-89.

NEVES, Marcelo. A constitucionalização simbólica. 3. ed. São Paulo: Editora WMF Martins Fontes, 2011.

REPÚBLICA ÁRABE UNIDA. Constituição provisória (1958). Provisional Constitution of the United Arab Republic, Cairo, 1958.

Constituição. The Constitution. Cairo, 1964.

SALHI, Ribhi. Egypt Upheaval 2011-2013: Is it the Two Revolutions or the Two Coups? An Analysis of a Complex Adaptive System. Illinois Political Science Review, v. 16, p. 93-122, 2016. Disponível em: <http://castle.eiu.edu/ipsa/IPSR\%20Fall\%20 2016.pdf>. Acesso em: 12 dez. 2016.

SCOTT, Rachel M. The Challenge of Political Islam: Non-muslims and the Egyptian State. Stanford: Stanford University Press, 2010.

SILVA, Maria Beatriz Nizza da. O conceito de liberdade política em Montesquieu. Revista de História, v. 38, n. 78, p. 415-423, 1969.

STILT, Kristen. "Islam is the Solution": Constitutional Vision of the Egyptian Muslim Brotherhood. Texas International Law Journal, v. 46, n. 1, p. 74-108, 2010. Disponível em: <http://www.tilj.org/content/journal/46/ num1/Stilt73.pdf>. Acesso em: 20 nov. 2016.

TADROS, Mariz. Copts at the Crossroads: The Challenges of Building Inclusive Democracy in Egypt. Cairo:The American University in Cairo Press, 2013. 
THE ECONOMIST. THE sad state of Egypt's liberals. 10 out. 2015. Disponível em: <https://www.economist. com/news/middle-east-and-africa/21672255-who-left-fight-democracy-sad-state-egypts-liberals>. Acesso em: 22 abr. 2018.

TRUBEK, David M. Max Weber sobre Direito e Ascensão do Capitalismo. Revista Direito GV, v. 3, n. 1, p. 151186, 2007. Disponível em: <http://direitosp.fgv.br/sites/direitogv.fgv.br/files/rdgv_05_pp151-186.pdf>. Acesso em: 15 nov. 2016.

VÁRNAGY,Tomás. O pensamento político de John Locke e o surgimento do liberalismo. In: BORON, Atilio A. (Org.). Filosofia política moderna: de Hobbes a Marx. Buenos A'ires: Consejo Latinoamericano de Ciencias Sociales; São Paulo: Universidade de São Paulo, 2006.

VATIKIOTIS, P.J. The History of Egypt: from Muhammad Ali to Mubarak. 3. ed. Londres:Weidenfeld and Nicolson, 1985.

WEBER, Max. Sociologia do Direito. In: WEBER, Max. Economia e Sociedade: Fundamentos da Sociologia Compreensiva. Tradução de Regis Barbosa e Karen Elsabe Barbosa. Brasília: Editora da Universidade de Brasília, 1999. cap. 7. p. 1-153. 


\title{
Egypt between Islam and liberalism: the constitutional trajectory of a hybrid state
}

\begin{abstract}
The purpose of this article is to analyze the expansion of the religious dimension in Egyptian politics with the adoption of the 1971 Constitution and how it was revised in the Constitutions of 2012 and 2014. For that, the political proposal of the Islamic tradition as well as that of the liberal tradition is presented, and the ways in which both coexist in Egypt, giving to the country a hybrid aspect. Then a summary of the Egyptian constitutional trajectory from 1923 to 1964 is exposed and, after that, the analysis of the Constitutions mentioned above is made. Finally, the final considerations show the impacts of manipulating the religious dimension on Egyptian constitutional documents and how it is instrumentalized to achieve political objectives.
\end{abstract}

Keywords: Constitution, Egypt, Hybrid State, Islam, Liberalism.

\section{Egipto entre el Islam y el liberalismo: la trayectoria constitucional de un estado híbrido}

\section{Resumen}

El objetivo de este artículo es analizar la expansión de la dimensión religiosa en la política de Egipto con la adopción de la Constitución de 1971 y cómo ésta fue modificada en las Constituciones de 2012 y 2014. Para ello, se presenta la propuesta política de la tradición islámica, así como la de la liberal, y las maneras en que ambas pasaron a convivir en Egipto, dando al país un aspecto híbrido. A continuación, una síntesis de la trayectoria constitucional egipcia de 1923 a 1964 es expuesta y, a continuación, se hace el análisis de las Constituciones arriba mencionadas. Por último, las consideraciones finales muestran los impactos de la manipulación de la dimensión religiosa en los documentos constitucionales egipcios y cómo se la instrumentaliza para alcanzar objetivos políticos.

Palabras clave: Constitución, Egipto, Estado híbrido, Islam, Liberalismo. 